\title{
Os estudos socioculturais do movimento humano e os 40 anos da Pós-graduação da EEFE-USP
}

http://dx.doi.org/10.11606/1807-55092017000nesp111

\author{
Soraia Chung SAURA* \\ Ana Cristina ZIMMERMANN* \\ *Escola de Educação \\ Física e Esporte, \\ Kátia RUBIO* \\ Universidade de São \\ Paulo, São Paulo, SP,
}

\begin{abstract}
A caminhada consiste em fazer um ir e vir incessante entre certezas e incertezas, entre o elementar e o global, entre o separável e o inseparável. Do mesmo modo, utilizamos a lógica clássica e os princípios de identidade, de não-contradição, de dedução, de indução, mas conhecemos seus limites, sabemos que em certos casos é preciso transgredi-los. Não se trata, portanto, de abandonar os princípios da ciência clássica - ordem, separabilidade e lógica -, mas de integrá-los num esquema que é, ao mesmo tempo, largo e mais rico ${ }^{1}$ (p.205).
\end{abstract}

\section{Introdução}

A Educação Física enquanto área científica é considerada recente em comparação à outras áreas do conhecimento mais tradicionais. Por conta disso e também pela amplitude dos fenômenos que tangem o movimento humano, este campo de estudos realiza intensa interface com outras ciências desde o seu surgimento. Há acentuada e vigorosa discussão ainda sobre se de fato, a Educação Física de um modo geral pode se configurar como ciência, como área de intervenção ou como ambos ${ }^{2-5}$.

No que tange a dimensão sociocultural do movimento humano, Guedes e Rubio ${ }^{6}$ apontam que na Escola de Educação Física e Esporte da Universidade de São Paulo, observa-se a presença dos Estudos Socioculturais do Movimento Humano desde o primeiro currículo, porém, a criação do Núcleo de Estudos Socioculturais do Movimento Humano (NESC) em 1985 ampliou o espaço para a investigação acadêmica nesta área.

A partir de 2003, há a estruturação do Centro de Estudos Socioculturais do Movimento Humano (CESCMH) e assim foram consolidadas e ampliadas as linhas de pesquisa, já não mais demarcadas pelas subáreas de conhecimento, a saber, a sociologia, a filosofia, a história, a psicologia ou a antropologia, mas pelos métodos e pelos objetos de pesquisa, ou seja, o movimento humano e suas interfaces com o Esporte, o Lazer e a atividade física de um modo geral. Também com objetos específicos como o Olimpismo $^{7-11}$, o jogo ${ }^{12-13}$, os jogos tradicionais ${ }^{14-15}$, o lazer e o brincar ${ }^{16-19}$, apontando uma tendência para a transdisciplinaridade, destacando sua complexidade. Atualmente, o CESCMH conta com três grupos de estudos em seu interior: o GEO - Grupo de Estudos Olímpicos; o OPE Observatório de Psicologia do Esporte; e o PULA - Grupo Interdisciplinar de Estudos em Atividade Física, Esporte e Lazer.

Deste modo, este artigo enfatiza como no seu fazer, as humanidades buscam ampliar conceitos - ao invés de estabilizá-los. Inicialmente discute-se acerca de elementos importantes que caracterizam a área, um escopo de metodologias e análises próprias. Em seguida, apresentam-se os desafios enfrentados pelas pesquisas socioculturais nos estudos da Educação Física e do Esporte e o que é desenvolvido no Centro de Estudos Sociocultural do Movimento Humano. Pretende-se evidenciar o potencial de construção de conhecimento da Educação Física, na valorização $\mathrm{da}$ interdisciplinaridade e no reconhecimento da pluralidade teórica da área na construção de sua identidade científica. 


\section{Interdisciplinaridade}

Considerando a história recente da Educação Física no âmbito da ciência, a tentativa tem sido, nos últimos tempos, a de formular e estabilizar conceitos. Além de valer-se de metodologias emprestadas de outras áreas do conhecimento, timidamente metodologias específicas passam a surgir a partir deste campo de estudos. Realizamos intensa interface com outras áreas e uma análise inicial demonstra essa diversificação, que envolve termos, conceitos, metodologias e análises. Talvez precisamente resida aí a sua riqueza enquanto campo de pesquisa, sempre interdisciplinar - e que pode, por sua vez, oferecer um modelo mais expandido de possibilidades também para outras áreas do conhecimento que hoje buscam integralidade entre as especificidades.

Definido por $\mathrm{VAZ}^{5}$ como um "território de fronteira”, a educação física e o esporte, em suas múltiplas relaçóes com outras ciências, apontam a potência de um objeto ou fenômeno abordado por meio de diferentes perspectivas. Mas o que pode parecer limitante na construção de uma área de conhecimento - com conceitos específicos pode também ser compreendida como abertura de possibilidades, quando se trata de pensar o conhecimento e a ciência em si. Se emprestarmos a definição mais ampliada de "fronteira" da geografia, compreenderemos que estas não são propriamente apenas limites, são "espaços entre dois"20. Neste sentido, "Elas operam como territórios potenciais de encontro, interfaces: elas se entrecortam, evidenciando vários mundos e poderes que se atravessam" ${ }^{\prime 21}$ (p.57). Neste aspecto, as fronteiras que se estabelecem entre diversos campos de pesquisa convocam a "vivência da alteridade, de abertura ao outro. As fronteiras são permeadas por esse risco: $\mathrm{o}$ outro"21 (p.57). Este outro é a diferença, o que nos provoca, o que nos permite pensar para além do que já temos ou somos.

Educação física/ciências do esporte encontram uma fronteira, quando procuram por um objeto que lhes confira cientificidade, ou mesmo por um objeto que queiram estudar. Se quisermos entender as múltiplas expressōes do corpo, inclusive seus movimentos - plenos de significados que cruzam natureza e cultura e que são, portanto, plenos de humanidade -, esbarramos em dois impasses. O primeiro diz que o corpo e seus movimentos, ou, por outra, a educaçáo do corpo, possuem tal multivocalidade que é improvável que se consiga estudá-la dentro de apenas uma matriz disciplinar ${ }^{5}$ (p.168).

O próprio conceito de corpo envolve ambiguidades ao pensarmos sob a perspectiva da objetividade ou subjetividade, se temos um corpo ou se somos um corpo, se biológico, cultural ou ambos. O corpo como biologia é materialidade, como cultura, uma construção simbólica, solicitando sempre novas elaboraçóes. O corpo é o "dentro" e é o "fora", dita escolhas de alimentaçáo, de modos de conduta. Se é aceitável, se é higiênico. Materializa nossos desejos, nossa sexualidade. Revela limites e questionamentos morais, psíquicos, sociais ${ }^{22}$. Submete-se a normatizaçóes e instituições. Pode ser também virtual: sem contornos delimitados de espaço e tempo. Traz conteúdos diversos como o esforço da permanência, a negação do perecível, a negação da morte. A atualização da experiência da dor e do sofrimento, no corpo. A memória de uma comunidade ou da história de vida.

Por estas razóes, amplificaçóes e ramificaçóes, as ciências humanas dentro da educação física hoje buscam não fechar e estabilizar os conceitos em determinados enquadramentos - é da natureza de sua reflexão ampliar e diversificar questionamentos até os limites de suas possibilidades, para que possamos ter olhares variados sobre um mesmo fenômeno. Também, por possibilitar um olhar menos técnico e mais humanizado sobre o movimento humano.

A área da medicina, por exemplo, tem trazido a necessidade de uma formação que agregue, para além de todos os conhecimentos técnicos acumulados, a humanização de seus procedimentos técnicos e profissionais, por longo tempo colocados em escanteio diante da formação especialista e específica, táo importante para os avanços da área. Rios e Schraiber ${ }^{23}$ avaliam que formar bons profissionais técnicos é hoje insuficiente para termos um bom profissional médico. Nas áreas da saúde, notadamente, as palavras humanização, humanidades, humanitário, relaçóes pessoais, intersubjetividade entre outras, aumentam de incidência vertiginosamente, demonstrando a necessidade de um conhecimento humano que busque o todo e as relações que se estabelecem entre as partes. Dentro das escolas de medicina tradicionais, criam-se espaços e laboratórios de humanidades, objetivando discutir aspectos tradicionalmente não 
abordados em áreas intrínsecas às biológicas. Pois além da cura do corpo, há a incerteza provocada pelas limitaçốes da técnica, as pessoas reais e as incertezas humanas. Estes são, aliás, problemas de todas as geraçóes, esquecidas pelas ciências da saúde por um longo período em detrimento do que tange o conhecimento cada vez mais específico e compartimentado em suas especialidades.

Como a medicina, também a educação traz um tema fundamental para a humanidade: a transformação da criança em adulto e a transmissão do conhecimento acumulado de uma geração à outra. Ambas - saúde e educação - discutem a permanência do homem no mundo, o tempo que não se encerra em si mesmo mas traz continuidades, os ciclos que fazem e se refazem. Entretanto, a pedagogia, área da ciência da educação, embora calcada em preceitos das humanidades, acompanha a tradição científica ao seguir o modelo das ciências naturais - compartimentando seu saber, visando seu aprofundamento. Ainda que esta seleção e separação sejam necessárias, seu excesso tem gerado hoje discussões em torno de disciplinas específicas que não dialogam entre si, grades curriculares que

\section{Contextos e textos}

Como um dos campos de uma ciência ainda em construção, a área sociocultural tem enfrentado grandes desafios desde seu surgimento no cenário das discussões da Educação Física e do Esporte. Como movimento inicial, destacamos o esquadrinhamento e o empenho pela compreensão de áreas tais como história, sociologia, psicologia, antropologia e filosofia; separadamente. Foi importante compreender como cada uma das áreas de humanidades estabelece o diálogo acerca do movimento humano em suas diferentes abordagens e olhares, pois que muitas dessas áreas específicas produziram questôes dentro do campo de análise próprios do domínio do movimento humano. A educação física, o esporte e o lazer enquanto fenômenos mais amplos são áreas de interesse das humanidades em geral. Não por acaso, grande parte das produçôes acadêmicas sobre questóes dessa área específica estão concentradas e são produzidas ainda por grupos de pesquisa sediados nas humanidades. Mais recentemente, já dentro do contexto da Educação Física, a intensificação foi pela absorção desses outros saberes e seus modos de fazer ciência. não intercambiam o conhecimento e a extenuante tentativa pedagógica de ruptura deste modelo. Dentre algumas consequências práticas destas discussôes, a sujeição do aluno aos professores especialistas vai dando lugar à participação ativa, à autonomia de aprendizagem, às relaçóes cultivadas e à participação de todos na construção de conhecimento, que deste modo é elaborado de forma dialógica - e náo hierárquica - na relaçáo professor-aluno, mestre-aprendiz.

A complexidade, interdisciplinaridade complementariedade e concorrência ${ }^{1}$ é debatida em todas as áreas enquanto necessidade. Algo inerente da educação física, cuja tecnologia pode ser emprestada à outras áreas do conhecimento

A Educação Física não pode abrir mão de uma poderosa realizaçáo humana como a ciência, capaz de compreender/explicar e intervir no mundo com modos específicos. Mas, para tal, é necessária a existência de uma comunidade científica que construa o(s) método(s) científico(s) e que se veja como parte da sociedade - origem e destino dos conhecimentos por ela produzidos $^{2}$ (p.195).

Aliada às dificuldades iniciais que requerem a inauguração de um campo, esteve associada uma forma de reconhecer e abordar problemas bastante dissonante do fazer pesquisa valorizado pela política nacional de ciência e tecnologia. Muitas questóes presentes nas discussôes das humanidades são frequentemente abordadas também por autores da Educação Física: a valorização de uma forma de produção incompatível com a forma de fazer pesquisa e produzir conhecimento, a necessidade de produção em grande velocidade, a valorização de indicadores quantitativos de produção, a instrumentalização do saber, entre outros. Tais problemas não são específicos da área sociocultural na Educação Física, mas das ciências sociais e humanas de um modo geral em relação às demais ciências. Ainda assim, não se questiona a importância da área de humanidades, principalmente no que tange os estudos do homem, sociedade e cultura, e as reflexões críticas, que incluem também debates acerca dos próprios rumos científicos e do fazer ciência $^{24}$. 
Ao longo deste período inicial dentro do campo da Educação Física, percebe-se que a tentativa de adequar-se a parâmetros de áreas completamente diferentes ameaça, senão a sobrevivência, a identidade ou originalidade da contribuição das humanidades. Na própria história das ciências, vêse que acomodaçôes de áreas supostamente mais fracas a áreas mais fortes - de acordo com o "status quo" da época - em busca de obtençáo de recursos e prestígio por exemplo, não se configurou como um ganho para a ciência-em-si, ao contrário.

De todo modo, o diálogo da Educação Física com as ciências sociais e humanas não se estabeleceu por acaso, mas por necessidade. Tal diálogo se mostra indispensável ao tratarmos de fenômenos humanos com maior amplitude social, política e econômica; e talvez esta questáo precise ser continuamente retomada: porque existem pesquisas da Educação Física que buscam necessariamente o referencial das ciências sociais e humanas?

Talvez porque em uma área multidisciplinar não busquemos as mesmas respostas, sequer temos as mesmas perguntas e especialmente, não compartilhamos a mesma forma de conduzir a investigação. A justificativa para uma área que se fez necessária pelas suas peculiaridades está justamente na sua diferença, originalidade. O que nos aproxima é o desejo de buscar o conhecimento acerca do movimento humano e tudo o que o tangencia. Assim, justificativas que não calcadas na própria investigação, dúvida e curiosidade operam em outra lógica que não o propósito da ciência de muitas vezes questionar algumas certezas, lógicas ou estruturas.

No que tange por exemplo, as publicaçóes da área, temos clareza de que mais do que "rankings" de produtividade, o objetivo maior para a ciência é o desejo de um diálogo expressivo, que conduza o pensamento a algo que sem tais formulaçóes náo seríamos capazes de atingir. Assim, o que se espera com as publicações em nosso campo é aparentemente simples: textos que anunciem boas pesquisas, comprometidas com a busca de profundidade nas discussôes, que por sua vez sustentem e fomentem outras conquistas e outros questionamentos. Também, na clareza do constante dilema entre qualidade e quantidade, consideramos que a melhor estratégia seja a de manter a qualidade e não inverter a lógica ao tentar adequar-se a parâmetros que podem comprometer a própria identidade da área. Certamente esta não é uma questão simples, pois a correspondência a determinados indicadores de avaliação também está associada a outros elementos da "sobrevivência acadêmica", tais como financiamentos para pesquisa, participação nos programas de pósgraduação, entre outros.

Entendemos que pesquisa é busca, rigor, vigor, curiosidade investigativa. E o desafio das humanidades na Educação Física parece ter sido buscar estratégias de qualificação em si mesma muito mais que de adequação ou adaptação a um determinado projeto que não é compatível com sua identidade ou proposta. As ciências sociais e humanas justamente auxiliam na reflexão acerca da forma como nos elaboramos em sociedade, dos caminhos atuais do fazer científico e na reorientação permanente de questóes, contribuindo com um debate oportuno e necessário sobre os temas que nos envolvem.

A já conhecida inversão da lógica da publicação no meio acadêmico, que por princípio tem por objetivo divulgar a pesquisa, promover o conhecimento e fomentar a discussáo; para o ato de publicar a fim de corresponder a exigências externas, gera problemas já amplamente discutidos: superficialidade, legitimação de estratégias de produção de publicaçóes (e não necessariamente de pesquisa), entre outros subterfúgios. Algumas destas, se já questionáveis em outras áreas, tornam-se completamente incoerentes com a proposta geral das ciências sociais e humanas, tais como a fragmentação de pesquisas, a replicação de discussôes, entre outras. A cooperaçáo entre autores, por exemplo, é extremamente profícua, mas nesta área demanda ampla discussáo e, portanto, tempo. Mais do que isso, um respeito a outra temporalidade, própria das reflexóes e pesquisas das humanidades. Espera-se que a publicação científica contribua para a solução dos problemas, para a reformulaçáo de questôes, para a reflexấo acerca de caminhos e possibilidades nas diversas esferas da atuaçáo humana. Com clareza sabemos que a publicaçáo deve ser uma decorrência da pesquisa, uma divulgação de discussóes e debates contextualizados com resultados que contribuam com o conhecimento. Deste modo, nesta área valoriza-se o texto com potência expressiva, um discurso com argumentação consistente o suficiente para ultrapassar discursos previamente elaborados ou uma suposta neutralidade na mera apresentação de fatos ou dados. Os discursos científicos muitas vezes têm a ambição de traduzir "uma verdade da natureza em si", entretanto o cuidado com o texto lembra que "o que queremos dizer não se mostra, fora de toda palavra, como pura significaçáo" 25 (p.175). Portanto, ressalta-se a importância da linguagem 
na constituição de objetos, e mais ainda, do uso expressivo da palavra. Aqui, o rigor e também a dificuldade está em elaborar este dizer expressivo, um texto que é ele próprio questionamento e discussão. Rigoroso porque não se cansa do exercício de busca. Escrever deste modo, é também pesquisar, dialogar com autores, questionar, propor caminhos para a reflexão. Há um exercício crítico na própria elaboração textual.

Deste modo, a grande contribuição da área de humanidades não é apenas a acumulação de conhecimentos que poderiam se perder senão pelo registro, mas sua capacidade de viabilizar o diálogo entre autores, teorias e questóes, que permite aos anteriores uma nova atualidade. Assim, não se

\section{Atualidade e desafios futuros}

Tendo as ciências de um modo geral compartimentado conhecimentos até o limite de suas possibilidades, a tentativa hoje é de reintegrálos de alguma maneira - ou pelo menos em alguns momentos - em um todo orientado, menos dissociado do conjunto que nos forma. Diferentemente das ciências duras, que estáo em busca permanente de estabilizar e fechar conceitos, metodologias e formas de análise, a área sociocultural na Educação Física busca o contrário: a amplitude e diversificação de seus objetos de pesquisa no que tangem fenômenos táo impregnados na sociedade atual como o esporte, o lazer e a atividade física. A elaboraçáo de novas metodologias de pesquisa, mais adequadas à essa complexidade científica, estão em franca construção. Não basta apenas emprestar metodologias prontas de diferentes áreas, mas reelaborá-las a partir da necessidade do nosso campo de investigação.

Deste modo, ao longo destes 40 anos de pósgraduação a Escola de Educação Física da USP protagoniza esta ampliação. A área de estudos socioculturais tem participado desta construção na medida em que também se fortalece a partir de diferentes frentes abrangendo questóes como a mídia esportiva, psicologia social do esporte, história oral e o Olimpismo, Lazer, Jogos Tradicionais, Filosofia do Esporte - temas que dialogam com diferentes áreas de conhecimento como a sociologia, a filosofia, a história, a psicologia, favorecendo o entendimento do objeto estudado, e dificultando o enquadramento da pesquisa e sua consequente publicação nos trata apenas de uma apresentação de resultados, mas de uma reflexão própria da pesquisa, e consequentemente, sobre a presença desta forma de pensar no mundo.

Entendemos que hoje, dentro do campo do movimento humano, o principal desafio é atender a demanda de um objeto de investigação que é amplo e complexo, uma vez que responde a diversos fenômenos associados à atividade física, esporte e lazer. Do mesmo modo, a ampliação de conceitos, a inovação e adequação de metodologias, passando por critérios de pesquisa éticos diferentes dos tradicionalmente empregados para áreas das ciências biológicas, são construídas no interior da área sociocultural da Educação Física.

periódicos já delimitados como pertencentes a uma área específica. Esta construção se dá inicialmente pelo diálogo com as ciências sociais e humanas até a consolidação de referencial e metodologias próprias para a Educação Física e Esporte. Na EEFE essa produção marca sua presença em pesquisas como Memórias Olímpicas por Atletas Olímpicos Brasileiros, cujo objetivo foi registrar a trajetória do esporte olímpico brasileiro a partir da narrativa dos atletas que protagonizaram essa realização. Ao longo dos 17 anos da pesquisa o que se observou foi não apenas a construção de um método detalhado ${ }^{10-11,26-29}$ como também a imersão em um universo rico em informaçóes de caráter subjetivo ${ }^{8-7,30}$ que levaram diferentes pesquisadores ao encontro de referências que permitiram um conhecimento maior e mais detalhado daquilo que foi e é o esporte no Brasil ${ }^{31-42}$. Se no princípio a motivação metodológica foi o estudo do imaginário para compreensão da dinâmica do esporte contemporâneo ${ }^{30,43-44}$, a aproximação com os protagonistas do espetáculo esportivo levou a uma alteração de rota e ao encontro com a história oral ${ }^{43-45}$. Ao longo dos anos ela se desdobrou em história de vida em função dos elementos individuais e sociais presentes nessa construção, para se estabelecer, no presente na condição de narrativas biográficas $^{10,46-47}$, considerando as características subjetivas no discurso daqueles que narram sua história, que já não é mais apenas privada, posto que o agente disparador da narrativa é um fato público vivido pelo sujeito, ou seja, a participação em uma 
edição de Jogos Olímpicos. A síntese desse processo publicada em momentos distintos ${ }^{9,11,29}$ aponta para o interesse que o fazer da pesquisa, e do modo de trabalho do Grupo de Estudos Olímpicos, despertou ao longo desses anos.

A partir de 2010, com o ingresso de novos recursos humanos na EEFE, a área se fortalece para novas amplitudes de ensino, pesquisa e extensão. O lazer adentra o campo de argumentação e as atividades físicas e esportivas de um modo geral passam a ser debatidos na perspectiva da antropologia e da filosofia, em especial da fenomenologia; buscando metodologias próprias e adequadas dentro deste escopo. Surgem novos campos de pesquisa e abremse mais espaços para diálogos com a comunidade nacional e internacional.

Sobre o Lazer, por exemplo, a Escola tem realizado o exercício de aproximá-lo das questóes mais filosóficas e universais do movimento humano, ampliando o leque de possibilidades de abordagem - uma vez que a área mais tradicional de Estudos do Lazer, dentro da Educação Física, está calcada na sociologia urbana. Deste modo, o Lazer tem sido alargado para repensar modos de vida, ideias e valores ${ }^{17-18,48}$.

Mais do que ser útil a algo, defendemos o Lazer como um fim em si mesmo, que encerra em si inúmeras possibilidades - não tendo serventia, pode aproximar-se de outra maneira, sem subserviência, a todos os fins ${ }^{17}$. Mais do que "tempo" de Lazer podemos dizer de outros modos de existência e resistência à questáo do trabalho e do tempo livre, que perdem hoje seus limites divisórios tradicionais como trabalho $\mathrm{x}$ diversão, seriedade $\mathrm{x}$ brincar ${ }^{49}$. Na perspectiva ontológica do "Quem sou" estas dicotomias são sempre experienciadas em reversibilidade, complementariedade, recursivamente, sem hierarquias, sem modos certos ou errados, apenas como dilatadores de consciência e possibilidades.

A esta temática uniu-se a questáo dos Jogos Tradicionais, em franco desenvolvimento na área, em razáo de sua diversidade, de seu caráter de inclusão, resistência e universalidade, apresentando outros modos possíveis de olhar e viver a sociedade e o ambiente, o esporte, as atividades físicas e de lazer. Os Jogos Tradicionais ganharam espaço e importância quando pensados em sua dimensão constituinte e estruturante para o movimento, principalmente sob a perspectiva de práticas não formais de atividade física.

Avançamos no debate com a realização do I Seminário Internacional de Jogos Tradicionais e Lazer em 2012, que congregou renomados pesquisadores brasileiros, também da Ásia, da Europa e do continente Americano. Com duas publicaçóes, uma nacional ${ }^{14} \mathrm{e}$ outra internacional ${ }^{15}$ em 2015 a Escola esteve presente nos Jogos Mundiais dos Povos Indígenas, acompanhando as discussóes que envolvem os objetos e sujeitos deste evento; também participou do III Encontro Panamericano de Jogos e Esportes Autóctones e Tradicionais (III EPJEAT) em Palmas, TO; recebeu integrantes da Federação Mexicana de Jogos e Esportes Autóctones e Tradicionais e realizou o II Seminário Internacional de Jogos Tradicionais e Lazer em 2017, ampliando as discussóes dos Jogos Tradicionais - antes mais focado nos Jogos Indígenas e nas brincadeiras populares para a produção realizada no interior das populações tradicionais - indígenas, quilombolas, caiçaras, ribeirinhas, entre outras - um vasto recurso brasileiro de modos de vida e referências para a sociedade atual. Ainda em 2017 participamos do IV Encontro Panamericano de Jogos e Esportes Autóctones e Tradicionais (III EPJEAT), levando as concepções e atualizaçóes do II Seminário Internacional de Jogos Tradicionais e Lazer.

Questôes de Ética e Estética adentraram a unidade, no interior de disciplinas ou em eventos ao corpo discente. Também sob a perspectiva filosófica, outros temas como justiça, equidade, gênero, "doping", aprimoramento genético, uso de tecnologia, incapacidade esportiva, o significado da vitória, a exposição ao risco, a aventura ${ }^{50}$, valores esportivos, o erro, a dor, a violência, a competiçáo, a igualdade, a traição, a decepção, o "fair play", as regras, as habilidades, fornecem subsídios para discussōes e análises estimulantes e desafiadoras. Falamos de uma área abrangente, ao mesmo tempo de um campo específico de indagaçóes sobre a ciência esportiva, notadamente conhecida por debater questôes ortodoxas e provocativas, com rigor conceitual e epistemológico, promovendo o debate e a reflexão. Nesta área, estudos e pesquisas no Brasil e na América Latina são relevantes em diferentes grupos de pesquisa e universidades, porém não unificados nacionalmente ${ }^{51}$. Internacionalmente, falamos de uma área amplamente reconhecida, instigante e instigadora, abordando questôes em torno do esporte com o rigor metodológico da filosofia, que repensa e faz pensar a própria ciência esportiva $^{52}$. Áreas como epistemologia, metafísica, lógica, ética, estética, fenomenologia, filosofia aplicada, comparada ou analítica unem-se no propósito de manter uma precisão epistêmica a 
fim de investigar e aprofundar temáticas variadas da educação física e do esporte. Desde 2011 o CESC/EEFE tem mantido diálogo constante com a comunidade internacional de pesquisadores em filosofia do esporte, que se intensifica pela participação nos eventos internacionais e conselho diretivo da Internacional Association for the Philosophy of Sport (IAPS) a na criação e participação no conselho diretivo da Associação Latina de Filosofia do Esporte (ALFID). A ALFid constituiu-se em novembro de 2013 objetivando fortalecer os estudos e análises do esporte como fenômeno filosófico no âmbito das línguas latinas, quais sejam, espanhol, francês, italiano e português. Com a intensificação de sua participação neste debate a EEFE sediará em 2018 o 3o. Congresso desta associação. Importante esclarecer que estes grupos adotam o termo "esporte"

\section{Considerações finais}

Vimos que as áreas da Educação Física e do Esporte são consideradas recentes em relação a outras áreas do conhecimento mais tradicionais, e têm avançado na implementação de novas metodologias e formas de análise, com as quais as humanidades contribuem. Em suas múltiplas relaçôes com outras ciências, as humanidades apontam a potência de um objeto ou fenômeno abordado por meio de diferentes perspectivas. E o que pode parecer limitante na construção de uma área de conhecimento - como a Educaçáo Física e o Esporte - pode também ser compreendido como abertura de possibilidades, quando se trata de pensar o conhecimento e a própria ciência. As humanidades, por sua característica intrínseca de pensar a própria ciência-em-si e seus modos de fazer, reafirmam o campo científico da Educação Física e em seu significado mais amplo, referindo-se a todas as práticas corporais vinculadas ao universo da Educação Física, do Esporte e do Lazer.

O CESC mantem também regularmente, desde 2011 o Projeto Cinema e Corpo ${ }^{\mathrm{b}}$ que alimenta, com seus diálogos inter unidades, novos olhares sobre nossos objetos de estudos. Embora instituído inicialmente como projeto de cultura e extensão, este tem gerado publicaçôes acadêmicas e suscitado o interesse pela pesquisa ${ }^{53}$.

Seminários, encontros, aulas na pós-graduação e orientações unem-se ao propósito de qualificar a área, debater nossos objetos e implementar metodologias de pesquisa e formas de análise. Desta forma a pós-graduação na área dos estudos socioculturais na EEFE tem ampliado seu potencial para acolher diferentes temas de estudo.

do Esporte como área do conhecimento abrangente, interdisciplinar, complexa e autônoma.

Ao longo destes 40 anos de Pós-graduação a Escola de Educação Física da USP protagoniza uma significativa ampliação do campo de estudos da área de estudos socioculturais. Esta construção se dá inicialmente pelo diálogo com as diferentes ciências sociais e humanas até a consolidação de referencial e metodologias próprias para a Educação Física e Esporte.

Assim, as diferentes áreas e possibilidades de pesquisa que de um modo geral compóem a pósgraduação na EEFE fazem jus ao pioneirismo desta instituição. Não se trata apenas de corresponder a orientaçôes ou flutuaçóes das políticas educacionais, para pesquisa e pós-graduação, mas também de orientar as discussões que regem tais parâmetros.

\section{Notas}

a. Além da realização da conferência anual, em sua 45 edição, a IAPS publica o Journal of the Philosophy of Sport, reconhecido como um dos mais respeitados meios para comunicação do pensamento filosófico contemporâneo em relação ao esporte.

b. O Projeto Cinema e Corpo (CESC - EEFE-USP e CINUSP Paulo Emílio), desde 2011 visa aproximar reflexóes das áreas de Esporte, Educação Física e Lazer da área de humanidades, tendo o cinema, o corpo e o movimento como pontos de intersecção. Realiza exibições de filmes seguido de debate com especialistas de diversas áreas, em interface com a extensão, a pesquisa e a graduação. 


\section{Referências}

1. Morin E, Le Moigne J-L. A inteligência da complexidade. São Paulo: Peirópolis; 2000.

2. Betti M. Educação física como prática científica e prática pedagógica: reflexôes à luz da filosofia da ciência. Rev Bras Educ Fís Esporte 2005;19:183-97.

3. Bracht V. Educação física \& ciência: cenas de um casamento (in)feliz. Ijuí: Unijuí; 1999.

4. Lovisolo H. Hegemonia e legitimidade nas ciências do esporte. Motus Corporis. 1996;3:51-72.

5. Vaz AF. Educação do corpo, conhecimento, fronteiras. Rev Bras Ciênc Esporte. 2000;24:161-72.

6. Guedes CM, Rubio K. Estudos socioculturais da educação física na Escola de Educação Física e Esporte: o que foi, o que tem sido e o que deverá ser. Rev Paul Educ Fís. 2004;18(N esp):83-8.

7. Rubio K. Heróis olímpicos brasileiros. São Paulo: Zouk; 2004.

8. Rubio K. Medalhistas olímpicos brasileiros: memórias, histórias e imaginário. São Paulo: Casa do Psicólogo; 2006.

9. Rubio K. Do imaginário esportivo ao mito olímpico contemporâneo: contribuiçóes do Grupo de Estudos Olímpicos da Universidade de São Paulo. In: Moragas M, DaCosta L, organizadores. Seminários España-Brasil 2006. Bellaterra: Universitat Autònoma de Barcelona; 2007. v.1.

10. Rubio K. Memórias e narrativas biográficas de atletas olímpicos brasileiros. In: Rubio K, organizadora. Preservação da memória: a responsabilidade social dos Jogos Olímpicos. São Paulo: Laços; 2014. p.103-17.

11. Rubio K. Atletas olímpicos brasileiros. São Paulo: SESI-SP; 2015.

12. Zimmermann AC, Morgan J. The possibilities and consequences of understanding play as dialogue. Sport Ethics Philos. 2011;5:46-62.

13. Zimmermann AC, Saura SC. Jogo: sobre sproximaçôes e encontros. In: Bettine M, organizador. Estudos interdisciplinares em sociologia do esporte. São Paulo: Escola de Artes, Ciências e Humanidades; 2016. p.56-74.

14. Zimmermann AC, Saura SC, organizdoras. Jogos tradicionais. São Paulo: Laços; 2014.

15. Saura SC, Zimmermann AC, organizdoras. Tradicional games. São Paulo: Laços; 2015.

16. Saura SC, Meirelles R. Brincantes e goleiros: consideraçóes sobre o brincar e o jogo a partir da fenomenologia da imagem. In: Correia WR, Muglia-Rodrigues B, organizadores. Educação física no ensino fundamental: da inspiração à ação. São Paulo: Fontoura; 2015. p.35-60.

17. Saura SC. A pedagogia do movimento na perspectiva do lazer. In: Basso L, Correa W, organizadores. Pedagogia do movimento do corpo humano. Várzea Paulista: Fontoura; 2013.

19. Saura SC, Zimmermann, AC. Educação corporal na perspectiva do lazer. In: Carreira Filho D, Correia WR, organizadores. Educação corporal: entre anúncios e denúncias. Curitiba: CRV; 2016. v.17, p.31-44.

18. Saura SC. O imaginário do lazer e do lúdico anunciado em práticas espontâneas do corpo brincante. Rev Bras Educ Fís Esporte. 2013; 8: 1-13.

20. Certeau M. A invenção do cotidiano: artes de fazer. Petrópolis: Vozes; 2008.

21. Hissa C, Nogueira M. Cidade-corpo. Rev UFMG. 2013;20:54-77.

22. Zimmermann AC, Morgan JEM. Forsters' the machine stops: humans, technology and dialogue. AI \& Society. 2017; $1: 1-9$.

23. Rios IC, Schraiber LB. Humanização e humanidades em medicina: a formação médica na cultura contemporânea. Sao Paulo: Unesp; 2012.

24. Safatle WP. O mal-estar das ciências humanas. Rev Cult. 2009;138. [citado 3 abr 2017]. Disponível em: https:// revistacult.uol.com.br/home/o-mal-estar-nas-ciencias-humanas/.

25. Merleau-Ponty M. A linguagem indireta e as vozes do silêncio. São Paulo: Abril Cultural; 1980. (Textos selecionados - Os pensadores).

26. Rubio K. A história de vida como método e instrumento para a apreensão do imaginário esportivo contemporâneo. Motus Corporis. 2003;11:30-48.

27. Rubio K. Lembranças de memórias: a título de introdução. In: Rubio K, organizadora. Narrativas biográficas: da busca à construção de um método. São Paulo: Laços; 2016.

28. Rubio K. Memória, esquecimento e meta-história: entre Mnemosine e Letho. In: Rubio K, organizadora. Narrativas biográficas: da busca à construção de um método. São Paulo: Laços; 2016. p.39-56.

29. Rubio K. Marcos de uma caminhada: imaginário, método, intuição e mapas de pesquisa com narrativas biográficas. In: Leão L , organizador. Processos do imaginário. São Paulo: Laços; 2016. p.51-75.

30. Rubio K. O atleta e o mito do herói. São Paulo: Casa do Psicólogo; 2001.

118 • Rev Bras Educ Fís Esporte, (São Paulo). 2017 Ago; 31(N esp):111-19. 
31. Almeida WD, Rubio K. Three athletes, two countries and a single club: the process of identity formation of immigrant sailors in Brazil. Open Access Library J. 2017;4:1-12.

32. Giglio SS. Rubio K. A hegemonia europeia no Comitê Olímpico Internacional. Rev Bras Educ Fís Esporte. $2017 ; 31$.

33. Lima LT, Rubio K. O atleta e a experiência da hospitalização. Rev Bras Psicol Esporte. 2016;6:90-101.

34. Ferreira Junior NS, Rubio K. The career transition between basketball champions in the amateurism phase. Adv Social Sci Res J. 2015;2:52-9.

35. Perez CR, Rubio K. The understanding of Olympic values by Brazilian olympic athletes. Int J Human Social Sci Educ. 2014;1:37-43.

36. Rubio K. The participation of women in Brazilian Olympic sport. In: Hargreaves J, Anderson E, editors. Routledge handbook of sport, gender and sexuality. Oxon: Routledge; 2014. p.129-38.

37. Nunes AV, Rubio K. The Japanese immigration influence on the formation and development of Brazilian judo. Int J Sport Stud. 2013;3:108794.

38. Lico FAA, Rubio, K. The Brazilian position considering the boycott of 1980 Moscow Olympic Games In: Hofmann AR, Kruger M, editors. Olympia als bildungsidee: Beitrage zur olympischen Geschichte und padagogik. Munster: Springer VS; 2012. p.113-31.

39. Rubio K, Godoy MF. A representação de dor em atletas olímpicos brasileiros. Rev Dor. 2007;8:926-35.

40. Rubio K. O imaginário da derrota no esporte contemporâneo. Psicol Soc. 2006;18:86-91.

41. Rubio K, Carvalho AL. Areté, fair play e movimento olímpico contemporâneo. Rev Port Ciênc Desporto. 2005;3: 350-7.

42. Silva MLS, Rubio K. Superação no esporte: limites individuais ou sociais? Rev Port Ciênc Desporto. 2003;3:69-76.

43. Rubio K. O imaginário esportivo ou seriam heróis os atletas modernos? Motus Corporis. 2000:7:56-74.

44. Rubio K. Aspectos do mito do herói na constituição do imaginário esportivo contemporâneo. In: Votre S, Teves N, Costa VLM, Mourão L, organizadores. Imaginário e representaçôes sociais em educação física, esporte e lazer. Rio de Janeiro: Gama Filho/Laboratório do Imaginário e das Representaçóes Sociais; 2001.

45. Rubio K, Custódio D, De Pierro C, Guilherme C, Silva HR, Soares L. Histórias que contam a história: a memória do movimento olímpico brasileiro revivida por seus medalhistas. In: Turini M, DaCosta L, organizadores. Coletânea de textos em Estudos Olímpicos. Rio de Janeiro: Gama Filho; 2002. v.2, p.745-46.

46. Veloso RC, Rubio K. Objetos biográficos: tempos vivos para narrativas. In: Rubio K, organizadora. Narrativas biográficas: da busca à construção de um método. São Paulo: Laços; 2016. p.229-42.

47. Rubio K. Novas identidades e novas carreiras: a transição entre atletas olímpicos brasileiros. In: Rubio K, organizadora. Destreinamento e transição de carreira no esporte. São Paulo: Casa do Psicólogo; 2012. p.47-64.

48. Saura, S.C. A pedagogia do movimento na perspectiva do lazer. In: Basso L, Correa W, organizadores. Pedagogia do movimento do corpo humano. Várzea Paulista: Fontoura; 2012. p.121-40.

49. Saura, S.C. O imaginário do lazer e do lúdico anunciado em práticas espontâneas do corpo brincante. Rev Bras Educ Fís Esporte. 2014;28:163-75.

50. Zimmermann AC, Saura SC. Body, environment and adventure: experience and spatiality. Sport Ethics Philos. 2017; 11:155-68.

51. Torres CR, Campos DG. Philosophy of sport in Latin America. J Philos Sport. 2010;37:292-309.

52. Fraleigh WP. IAPS: past to future. J Philos Sport. 2012;39:1-10.

53. Saura SC, Zimmerman AC. Cinema e corpo. São Paulo: Pró-Reitoria de Cultura e Extensão Universitária/USP; 2016.

ENDEREÇO

Soraia Chung Saura

Escola de Educação Física e Esporte - USP

Av. Prof. Mello Moraes, 65

05508-030 - São Paulo - SP - BRASIL

e-mail: soraiacs@usp.br 